tal cleaning, ${ }^{15} \mathrm{HCW}$ education, and surveillance and isolation of new NICU admissions with $S$ marcescens infection or colonization terminated transmission. Extrinsically contaminated soap containing 1\% chlorxylenol, a phenol derivative, amplified a reservoir of $S$ marcescens, resulting in a discernible outbreak.

\section{REFERENCES}

1. Gorbach SL, Bartlett JG, Blacklow NR. Infectious Diseases. Philadelphia, PA: WB Saunders Co; 1992.

2. Yu VL. Serratia marcescens: historical perspective and clinical review. N Engl J Med 1979;300:887-893.

3. Villarino ME, Jarvis WR, O'Hara C, Bresnahan J, Clark N. Epidemic of Serratia marcescens bacteremia in a cardiac intensive care unit. J Clin Microbiol 1989;27:2433-2436.

4. Nakashima AK, McCarthy MA, Martone WJ, Anderson RL. Epidemic septic arthritis caused by Serratia marcescens and associated with a benzalkonium chloride antiseptic. J Clin Microbiol 1987;25:1014-1018.

5. Sautter RL, Mattman LH, Legaspi RC. Serratia marcescens meningitis associated with a contaminated benzalkonium chloride solution. Infect Control 1984;5:223-225.

6. Ehrenkranz NJ, Bolyard EA, Wiener M, Cleary TJ. Antibioticsensitive Serratia marcescens infections complicating cardiopulmonary operations: contaminated disinfectant as a reservoir. Lancet 1980;2:1289-1292.

7. McNaughton M, Mazinke N, Thomas E. Newborn conjunctivitis associated with triclosan $0.5 \%$ antiseptic intrinsically contaminated with Serratia marcescens. Canadian Journal of Infection
Control 1995; 10:7-8.

8. Barry MA, Craven DE, Goularte TA, Lichtenberg DA. Serratia marcescens contamination of antiseptic soap containing triclosan: implications for nosocomial infection. Infect Control 1984;5:427-430.

9. Morse LJ, Schonbeck LF. Hand lotions-a potential nosocomial hazard. N Engl J Med 1968;278:376-378.

10. Sanford JP. Disinfectants that don't. Ann Intern Med 1970;72:282-283.

11. Dixon RE, Kaslow RA, Mackel DC, Fulkerson CC, Mallison GF. Aqueous quaternary ammonium antiseptic and disinfectants: use and misuse. JAMA 1976;236:2415-2417.

12. Richardson DK, Gray JE, McCormick MC, Workman K, Goldmann DA. Score for neonatal acute physiology: a physiologic severity index for neonatal intensive care. Pediatrics 1993;91:617-623.

13. Maslow JN, Slutsky AM, Arbeit RD. Application of pulsed-field gel electrophoresis to molecular epidemiology. In: Persing DH, Smith TF, Tenover FC, White TJ, eds. Diagnostic Molecular Microbiology, Principles and Applications. Washington, DC: American Society for Microbiology; 1993.

14. Petersen NJ, Collins DE, Marshall JH. A microbiological assay technique for hands. Health Laboratory Science 1973;10:18-22.

15. Byers KE, Durbin LJ, Simonton BM, Anglim AM, Adal KA, Farr BM. Environmental contamination with vancomycinresistant Enterococcus faecium (VRE). In: Program of the Fifth Annual Meeting of the Society of Hospital Epidemiology of America, San Diego, CA; April 1995; P18. Abstract 17.

16. Centers for Disease Control and Prevention. Guideline for Handwashing and Hospital Environmental Control, 1985. Atlanta, GA: US Department of Health and Human Services, 1985.

\title{
Lack of Isolation Despite Respirator Use Leads to MDR-TB Outbreak
}

\section{Gina Pugliese, RN, MS Martin S. Favero, $\mathbf{P h D}$}

An outbreak of seven cases of multidrug-resistant (MDR) tuberculosis (TB) occurred in a hospital in Chicago, all on one floor. The outbreak involved six patients and one healthcare worker, all of whom had AIDS. Case-patient 1 was admitted to the hospital and placed in a private room, and workers were required to wear a high-efficiency particulate (HEPA) respirator. Case-patient 1 refused to remain in the room and was the source of infection for casepatient 2. Case-patient 2 remained in his room, but was the source of infection for case-patients $3,4,5$, and 6 . Case-patient 7, a healthcare worker, drew blood from case-patient 2 before a diagnosis of TB was made. Case-patients 1 and 2 never were placed in acid-fast bacilli (AFB)-isolation rooms (negative pressure with $>6$ air exchanges per hour), because these rooms were not available at the time. Case-patients 4, 5, 6, and 7 all were placed in newly installed AFB isolation rooms. Case-patient 3 did not have sputum samples smear- positive for AFB. Smoke-tube testing revealed that the private rooms used by case-patients 1 and 2 had positive air pressure in relation to the hall, and the AFB-isolation rooms had negative air pressure in relation to the halls. All seven Mycobacterium tuberculosis isolates were resistant to isoniazid and rifampin and had matching DNA fingerprints. Of patients exposed to Mycobacterium tuberculosis, those who developed TB had lower CD4+ T-lymphocyte counts and were more likely to be ambulatory than those who did not. Of the 75 exposed healthcare workers, the $11(15 \%)$ who had conversion on tuberculin skin testing were no more likely than those who did not have conversion to report that they always wore a respirator with a HEPA filter.

Several factors are believed to have contributed to this outbreak. Case-patients 1 and 2 both were infectious, and the flow of contaminated air from their rooms (which had positive air pressure in relation to the hall) facilitated the spread of infectious droplet nuclei throughout the outbreak floor. Organisms were spread to healthcare workers who did not directly care for a patient with TB and to one secretary who did not have patient-care responsibilities. In this situation, a respiratory protection program did not prevent transmission to healthcare workers. Case-patients 1 and 2 were placed on anti-tuberculosis medication either at admission or within 3 days of admission, but the delayed recognition of and inadequate therapy for MDR-TB could have contributed to transmission. The authors note that the excellent skintesting program facilitated the detection of new cases and that germicidal ultraviolet irradiation (which was not used in this facility) may be used as a supplemental environmental control measure to reduce concentrations of infectious droplet nuclei. Finally, a respiratory protection program alone cannot protect all healthcare workers from infection, especially those who work on the wards but do not enter patient rooms. Prompt identification of patients with TB and appropriate isolation need to be emphasized.

FROM: Kenyon TA, Ridson R, Luskin-Hawk R, et al. A nosocomial outbreak of multidrug-resistant tuberculosis. Ann Intern Med 1997;127: 32-36. 